\title{
Predictive Modeling for Glass-Side Laser Scribing of Thin Film Photovoltaic Cells
}

\author{
Hongliang Wang, Shan-Ting Hsu, Huade Tan, Y. Lawrence Yao \\ Department of Mechanical Engineering \\ Columbia University \\ New York, NY, USA \\ Hongqiang Chen, Magdi N.Azer \\ Laser \& Metrology System Lab \\ GE Global Research \\ Niskayuna, NY, USA
}

\begin{abstract}
Laser scribing of multilayer thin films is an important process for producing integrated serial interconnection of minimodules, used to reduce photocurrent and resistance losses in a large-area solar cell. Quality of such scribing contributes to the overall quality and efficiency of the solar cell and therefore predictive capabilities of the process are essential. Limited numerical work has been performed in predicting the thin film laser removal processes. In this study, a sequentially-coupled multilayer thermal and mechanical finite element model is developed to analyze the laser-induced spatio-temporal temperature and thermal stress responsible for $\mathrm{SnO}_{2}: \mathrm{F}$ film removal. A plasma expansion induced pressure model is also investigated to simulate the non-thermal film removal of CdTe due to the micro-explosion process. Corresponding experiments on $\mathrm{SnO}_{2}: \mathrm{F}$ films on glass substrates by $1064 \mathrm{~nm}$ ns laser irradiation show a similar removal process to that predicted in the simulation. Differences between the model and experimental results are discussed and future model refinements are proposed. Both simulation and experimental results from glass-side laser scribing show clean film removal with minimum thermal effects indicating minimal changes to material electrical properties.
\end{abstract}

\section{KEYWORDS}

Modeling, laser scribing, multilayer thin films, $\mathrm{SnO}_{2}: \mathrm{F}, \mathrm{CdTe}$, solar cell

\section{INTRODUCTION}

Thin-film solar cell is a promising technology to achieve a significant cost reduction in materials, large area deposition capability, and the use of cheap and flexible substrates. Cadmium telluride (CdTe) is the dominant thin film solar cell material in recent years because of its attractive pricing and stable performance at high temperature [1-2]. One of the most important manufacturing processes in the fabrication of thin film solar cells is monolithic cell isolation and series interconnection. These $\mathrm{P} 1, \mathrm{P} 2$ and $\mathrm{P} 3$ processes are also used in the commercial production of a-Si and CIGS $\left(\mathrm{CuInGaSe}_{2}\right)$ [35]. Interconnects must have low series resistance and high shunt resistance, and produce a minimum dead area between cells. Laser scribing offers narrower scribe widths and less damage in the surrounding material compared to the mechanical scribing. Laser scribing suffers from two manufacturing related drawbacks. Laser scribing has been shown to leave a heat-affected zone around the scribe which can cause poor isolation between cells and low shunt resistance. Laser scribing has also been shown to leave high positive ridges along the edge of the scribe line, possibly acting as electrical shorts [3].

In order to decrease the thermal effect of laser irradiation during processing, ultrashort pulsed lasers, such as picosecond and femtosecond lasers, are under investigation for scribing processes [6-7]. These lasers are complex and expensive, and regardless of pulse duration, material melting cannot be totally eliminated [4]. Glass side processing [8-9] has been shown to be more efficient than laser processing from the film side with reduced thermal effect. Film side laser scribing is governed by heating, melting and vaporizing of selective films. Glass side laser scribing is a thermal-mechanical process which involves stress induced material failure and removal rather than vaporization. The mechanical fracture and removal of film material during glass side scribing is commonly referred to as lift off or micro-explosion processing. During microexplosion processing, the laser irradiates through the 
transparent substrate and is fully absorbed in a very thin layer of the film at the interface. High pressure plasma is generated and expanded in the film. Plasma punches through the solid film above and the material is removed mechanically [10]. Micro-explosion processing is pronounced when the laser material penetration depth is much smaller than the film thickness. One example is that of CdTe irradiated with a green laser at a wavelength of $532 \mathrm{~nm}$. In this case a thin layer at the interface absorbs the entire laser pulse and induces the high pressure lift off of the solid film above. For some transparent conducting oxide (TCO) layers, such as ITO and $\mathrm{SnO}_{2}: \mathrm{F}$, penetration depths exceed that of the film thicknesses. In this case lift off does not happen during laser scribing. It is thus difficult to scribe TCO layers with low thermal effects using ns lasers.

Limited references exist on the numerical modeling of thin film removal processes. Bovatsek, et al. [5] studied the temperature distribution of a multilayer thermal model of aSi cells by ns laser pulse irradiated from the glass side, and suggested that a-Si films were removed by thermal stress when the applied laser fluence is less than the melting threshold, because the calculated stress value exceeded the yield stress. However, this model cannot show the spatial distribution of temperature, and no mechanical model is developed to simulate the thermal stress induced film removal process. There is also limited simulation effort on micro-explosion processing. The price of solar cells is mainly determined by the cell efficiency, which is sensitive to scribing quality. Numerical models of laser scribing processes that predict scribing width, cleanliness and thermal effect are important for determining the optimal processing conditions for producing minimum dead zones and electrical property degradation during scribing. In order to achieve this, an understanding of the different removal mechanisms is required.

In this paper, a 2D numerical model using Abaqus is developed to simulate $\mathrm{SnO}_{2}: \mathrm{F}$ and CdTe film removal via sequentially-coupled thermal-mechanical stress and microexplosion processes, respectively. Removal of $\mathrm{SnO}_{2}: \mathrm{F}$ film from soda lime glass substrate is carried out using $1064 \mathrm{~nm}$, 50ns laser irradiated from the glass side. Film removal geometry is studied by scanning electron microscopy (SEM) and optical profilometry, and scribe cleanliness is estimated by energy-dispersive $\mathrm{x}$-ray spectroscopy (EDX).

\section{BACKGROUND}

Since the entire layer of $\mathrm{SnO}_{2}: \mathrm{F}$ can absorb the laser energy uniformly due to its high laser penetration depth, $\mathrm{SnO}_{2}: \mathrm{F}$ is usually removed by laser ablation in industry resulting a heat-affected zone. Here, a film removal process of $\mathrm{SnO}_{2}: \mathrm{F}$ with low laser fluences (less than melting threshold) is investigated in order to have another scribing scenario with no thermal affects. It is found that the film is removed via brittle material cracking caused by the thermal-induced tensile stress without a phase change.
Regarding to CdTe, which has a lower laser penetration depth compared to its thickness $(2 \mu \mathrm{m})$, it is commonly removed by micro-explosion process. Because CdTe film is thick, it is difficult to be thermally ablated with a single pulse. High-pressure plasma is generated at the film/substrate interface while applying laser from the glass side, and the solid film above is lifted off during the plasma expansion. CdTe film breaks because of brittle material cracking during the plasma punching period, and the material at the plasma boundaries can be delaminated simultaneously. The film delamination is analyzed by the traction separation mechanism at the interface, which is implemented using cohesive elements in the simulation.

\section{Thermal stress analysis}

During laser irradiation, the temperature distribution in the films and glass substrate is governed by the heat equation

$$
\rho C_{p} \frac{\partial T}{\partial t}=\nabla \cdot(k \nabla T)+q(x, y, z, t)
$$

where $\rho, C_{p}, T, t$ and $k$, are density, specific heat, temperature, time and conductivity, $x, y$ and $z$ are the Cartesian coordinates, and laser power density $q(x, y, z, t)$ is defined by

$$
q(x, y, z, t)=q_{0} e^{-\kappa z} e^{-\frac{2\left(x^{2}+y^{2}\right)}{R_{0}^{2}}} e^{-4 \ln 2\left(\frac{t-t_{p}}{t_{p}}\right)^{2}}
$$

where $q_{0}, \kappa, R_{0}$ and $t_{p}$ are the peak power density, absorption coefficient, beam radius and pulse width. When a structure is constrained, thermal expansion causes thermal stresses. The thermal stress $\boldsymbol{\sigma}$ is determined by Hooke's Law, $\boldsymbol{\sigma}=\boldsymbol{E} \boldsymbol{\varepsilon}$, where $\boldsymbol{E}$ and $\boldsymbol{\varepsilon}$ are the Young's modulus and thermal strain, respectively. $\varepsilon=\boldsymbol{\alpha} \Delta T$ with $\boldsymbol{\alpha}$ thermal expansion coefficient and $\Delta T$ the temperature change.

\section{Brittle cracking analysis}

Removal of CdTe and $\mathrm{SnO}_{2}: \mathrm{F}$ films are considered as a brittle material cracking process. Under a stress, a brittle material undergoes an elastic deformation, followed by inelastic deformation if cracking occurs. The total strain of a cracked material is composed of elastic and cracking strain. Cracking strains are expressed as $e^{c k}=\left[\begin{array}{lll}e_{u u}^{c k} & e_{v v}^{c k} & e_{u v}^{c k}\end{array}\right]^{T}$ and the corresponding stresses are $t^{c k}=\left[\begin{array}{lll}t_{u u}^{c k} & t_{v v}^{c k} & t_{u v}^{c k}\end{array}\right]^{T}$ with $u$ and $v$ defining the local Cartesian system at the crack. Cracking initiates when the maximum principal tensile stress exceeds the failure strength of the material, as stated by the Rankine criterion [11]. Crack opening is caused by a tensile stress normal to the cracking plane. An actively opening crack, in which the stress being carried reaches the failure strength first and then reduces, is modeled as a function of the cracking strain, $t_{u u}^{c k}=f\left(e_{u u}^{c k}\right)$ which describes the material softening 
due to cracking. A cyclic crack, which continually closes and reopens, propagates as a function of the load history. The stress depends on the maximum crack opening in the cracking history shown as $t_{u u}^{c k}=f\left(e_{u u}^{c k}\right) \mid \max e_{u u}$. Once cracking initiates, shear stress contributes to the postcracking as well [12], and the shear behavior is dependent of the crack opening. As the cracking strain reaches the defined failure strain, the material fails and its ability to carry stress reduces to zero.

\section{Traction separation analysis}

Laser induced plasma expansion at CdTe film/substrate interface can delaminate the film from the substrate. Traction separation behaviors at the interface are considered. The traction stress vector, $\boldsymbol{t}$, consists of two components $t_{u}$ and $t_{v}$, which represent the normal and shear tractions. Corresponding displacements are $\delta_{u}$ and $\delta_{v}$, and the strains are obtained by $\varepsilon_{u}=\delta_{u} / T_{0}, \varepsilon_{v}=\delta_{v} / T_{0}$, where $T_{0}$ is the original thickness of the elements. Before interface damage occurs, the relationship between the traction stress and strain can be written as

$$
\boldsymbol{t}=\left\{\begin{array}{c}
t_{u} \\
t_{v}
\end{array}\right\}=\left[\begin{array}{ll}
K_{u u} & K_{u v} \\
K_{u v} & K_{v v}
\end{array}\right]\left\{\begin{array}{c}
\varepsilon_{u} \\
\varepsilon_{v}
\end{array}\right\}=\boldsymbol{K} \varepsilon
$$

where $K_{u u}$ and $K_{v v}$ are the stiffness in the principal directions, while $K_{u v}$ is the stiffness in the shear direction. $K_{u v}$ is assumed to be zero since uncoupled behavior between the normal and shear components is considered. Interface damage initiates when the quadratic nominal stress criterion is met [13]

$$
\left\{\frac{\left\langle t_{u}\right\rangle}{t_{u}^{0}}\right\}^{2}+\left\{\frac{t_{v}}{t_{v}^{0}}\right\}^{2}=1
$$

The value of $\left\langle t_{u}\right\rangle$ is 0 if $t_{u}<0$ or $t_{u}$ if $t_{u}>0$, because a purely compressive stress does not initiate damage. The material constants $t_{u}^{0}$ and $t_{v}^{0}$ determine the damage initiation normal to the interface and along the shear direction, respectively. When the criterion is reached, the stiffness of the cohesive material is degraded based on a damage evolution law. A scalar damage variable, $D$, is used to capture the stiffness degradation, and increases from 0 to 1 upon further loading after the initiation of damage. The stress components affected by the damage evolution, $\bar{t}_{u}$ and $\bar{t}_{v}$, are

$$
\begin{gathered}
\overline{t_{u}}=\left\{\begin{array}{cc}
(1-D) t_{u}, & t_{u}>0 \\
t_{u}, & t_{u} \leq 0
\end{array}\right. \\
\overline{t_{v}}=(1-D) t_{v}
\end{gathered}
$$

From Camanho and Davila [14], the scalar damage variable $D$ is given as

$$
D=\frac{\delta_{m}^{f}\left(\delta_{m}^{\max }-\delta_{m}^{o}\right)}{\delta_{m}^{\max }\left(\delta_{m}^{f}-\delta_{m}^{o}\right)}
$$

where $\delta_{m}^{\max }$ is the maximum value of the effective displacement defined as $\delta_{m}=\sqrt{\left\langle\delta_{u}\right\rangle^{2}+\delta_{v}^{2}}, \delta_{m}^{f}$ is the displacement at which the stress degrades to 0 , and $\delta_{m}^{o}$ is the displacement where the damage initiates. Eqs. (4) to (7) describe the failure behavior of the cohesive elements used in simulation. Once the failure criterion is met, the cohesive element is removed from calculation.

\section{Micro-explosion analysis}

When a target, i.e. CdTe, is irradiated by an intense laser pulse, the surface layer vaporizes into high pressure plasma and induces shock waves during its expansion. If the shock wave is confined, the pressure generated can be magnified by a factor of 5 times of that without a confinement medium [15]. The solid film is punched off by the high pressure during plasma expansion, and mechanical effects are induced. This processed is called the "lift-off" or "micro-explosion" mechanism [10]. The confined shock pressure induced by laser-produced plasma is estimated by Fabbro. et al. [16]. In the model, a fraction of the laser energy ionizes the material and generates plasma, and the plasma absorbed laser intensity $I(t)$ is given by [15]

$$
I_{P}(t)=A I(t)
$$

where $A$, is absorption coefficient of plasma, $P(t)$ is shock pressure, and $t$ is time. Shock wave impedance is expressed as $Z=\rho D$, where $\rho$ is density and $D$ is shock propagation velocity. Assuming a constant fraction $\alpha$ of internal energy be used to increase the thermal energy of the plasma, the following relations between shock pressure $P(t)$ and plasma thickness $L(t)$ can be derived [15]

$$
\begin{gathered}
\frac{d L(t)}{d t}=\frac{2 P(t)}{Z} \\
\left(\frac{Z}{2}+\frac{3 Z}{4 \alpha}\right)\left(\frac{d L(t)}{d t}\right)+\frac{3 Z}{4 \alpha} L(t) \frac{d^{2} L(t)}{d t^{2}}=I_{p}(t)
\end{gathered}
$$

It is assumed that shock pressure follows a Gaussian spatial distribution with its $1 / e^{2}$ radius proportional to the $1 / e^{2}$ radius of the laser beam. The shock pressure is expressed as a function of space and time [15]

$$
P(r, t)=P(t) \cdot \exp \left(-\frac{r^{2}}{2 r_{0}^{2}}\right)
$$

where $r$ is the distance from the laser beam center, and $r_{0}$ is the laser beam radius.

\section{EXPERIMENTAL SETUP}

Polycrystalline TCO $\left(\mathrm{SnO}_{2}: \mathrm{F}\right)$ films were deposited on $3.2 \mathrm{~mm}$-thick soda lime substrates using chemical vapor deposition (CVD) at $1100^{\circ} \mathrm{F}$. Film thickness was found to be about $400 \mathrm{~nm}$ through ellipsometry measurements.

Experiments were carried out using a Nd:YAG laser. The system delivered $50-\mathrm{ns}$ pulses at a $1 \mathrm{kHz}$ repetition rate and a wavelength of $1064 \mathrm{~nm}$. The $\mathrm{SnO}_{2}: \mathrm{F}$ films were 
cleaned with acetone in an ultrasonic cleaner for 5 minutes and then rinsed with methanol and distilled water prior to processing. The sample was mounted on a three-axis translation stage and irradiated by laser pulses focused by a $20 \mathrm{~mm}$ effective-focal-length objective lens. The focal plane was placed at the interface between $\mathrm{SnO}_{2}: \mathrm{F}$ and substrate while processing from glass side, and at the top surface while processing from film side, to create a circular beam spot with a diameter of $10 \mu \mathrm{m}$.

Laser treated samples were observed through SEM. Surface roughness and damage profiles were measured by optical profilometry. The chemical components of laser processed samples were investigated by EDX.

\section{RESULTS AND DISCUSSION}

\section{Simulation on $\mathrm{SnO}_{2}: \mathrm{F}$ film removal by thermal stress}

The Schematic of glass-side laser scribing of $\mathrm{SnO}_{2}: \mathrm{F}$ and CdTe in both simulation and experiments is shown in Fig. 1. $1064 \mathrm{~nm}$ and $532 \mathrm{~nm}$ ns laser beams are used for scribing $\mathrm{SnO}_{2}: \mathrm{F}$ and CdTe films, respectively. Sequentiallycoupled thermal and mechanical models are implemented to predict $\mathrm{SnO}_{2}: \mathrm{F}$ film removal by thermal stress. A 2D thermal model is created with a dimension of $100 \mu \mathrm{m} \times 50 \mu \mathrm{m}, 400 \mathrm{~nm}$ thick $\mathrm{SnO}_{2}: \mathrm{F}$ is on top of the soda lime substrate, and surrounding environment is air, shown in Fig. 2. A laser beam with a wavelength of $1064 \mathrm{~nm}$ is irradiated from glass side with a fluence of $1 \mathrm{~J} / \mathrm{cm}^{2}$, less than the damage threshold ( 4J/ $\mathrm{cm}^{2}$ for 1064nm@ 70ns) [3]. The laser energy source in the $\mathrm{SnO}_{2}: \mathrm{F}$ layer is written as [5]

$$
E(r, z, t)=\left(1-R_{g}\right)\left(1-R_{t}\right) \alpha_{t} I(r, z, t) e^{-\alpha_{t}\left(z-T_{g}\right)}
$$

where $I(r, z, t)$ is the incident laser pulse energy. $R_{g}$ and $\alpha_{t}$ are the reflectivity and absorption coefficient of $\mathrm{SnO}_{2}: \mathrm{F} . R_{t}$ and $T_{g}$ are the reflectivity and thickness of glass. Glass and film material properties are listed in Table 1. The highest temperature achieved in the film is $1900 \mathrm{~K}$ at $117 \mathrm{~ns}$, slightly less than the melting temperature of $\mathrm{SnO}_{2}: \mathrm{F}$ (1903K). In Fig.2, it is also shown that the temperature is uniformly distributed through the center of the film. Through thickness temperature uniformity is caused by the large penetration depth of $\mathrm{SnO}_{2}: \mathrm{F}$ at $1064 \mathrm{~nm}$ is around $2 \mu \mathrm{m}, 5$ times the film thickness.

The sequentially mechanical model uses the temperature field input obtained from the thermal model. The substrate is transparent to laser irradiation. Upon initial exposure the film expands quickly, inducing a compressive stress in the film due to the substrate confinement. Because the film is free to expand in the thickness direction, stresses in the film planar direction $\left(\mathrm{S}_{11}\right)$ is dominant. Compressive stresses do not lead to film cracking during the laser heating, as thermal expansion of the film is restricted by its surroundings. Crack initiation occurs when the film undergoes tensile loading. It is observed from numerical output shown in Fig. 3 that the film stress state is initially compressive during laser irradiation, quickly decreasing to zero after $\sim 2 \mu \mathrm{s}$ and becomes tensile until failure. After tensile failure stress is achieved, the material is removed and stresses drop to zero.

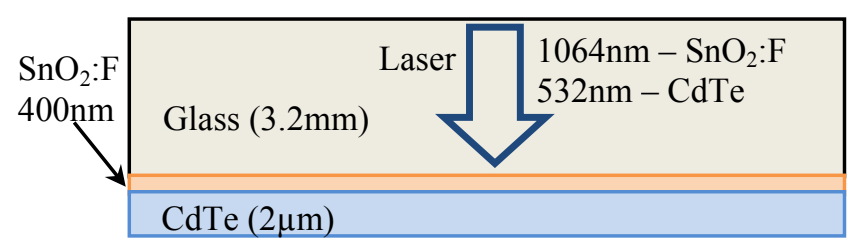

Figure 1. Schematic of glass-side laser scribing of $\mathrm{SnO}_{2}: \mathrm{F}$ and $\mathrm{CdTe}$ in both simulation and experiments.

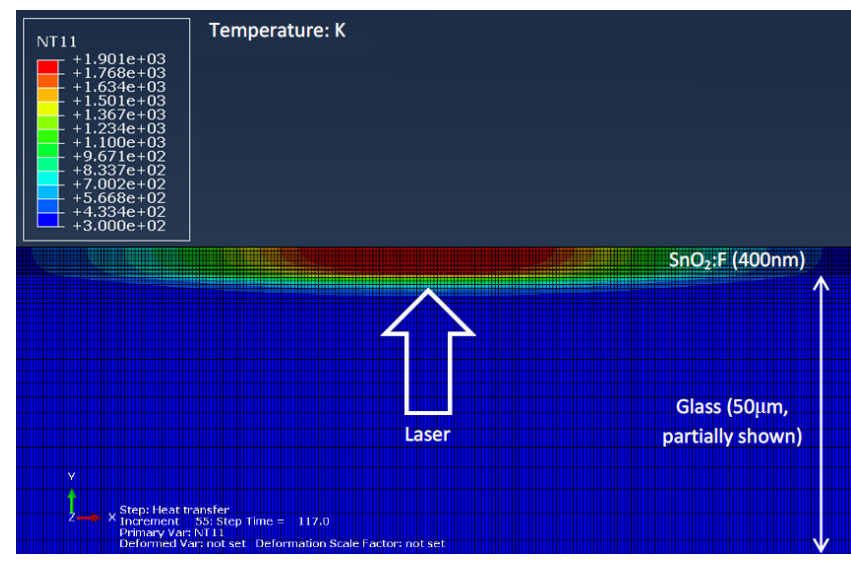

Figure 2. Simulation result of temperature distribution of $\mathrm{SnO}_{2}: \mathrm{F} / \mathrm{glass}$ multilayer thermal model at a fluence of $1 \mathrm{~J} / \mathrm{cm}^{2}$, showing the highest temperature of $1900 \mathrm{~K}$ at $117 \mathrm{~ns}$. The thickness of $\mathrm{SnO}_{2}: \mathrm{F}$ is $400 \mathrm{~nm}$, while the thickness of glass used in experiments is $3.2 \mathrm{~mm}$.

Table 1. Material properties using in the simulation

\begin{tabular}{|c|c|c|c|c|}
\hline Properties & Unit & CdTe & $\mathrm{SnO}_{2}: \mathrm{F}$ & Glass \\
\hline Density, $\rho$ & $\mathrm{g} / \mathrm{cm}^{3}$ & 5.85 & 6.95 & 2.52 \\
\hline Conductivity, $k$ & $\mathrm{~W} / \mathrm{mK}$ & 6.2 & 3.2 & 1 \\
\hline Latent Heat, $L$ & $10^{5} \mathrm{~J} / \mathrm{kg}$ & 2.092 & 3.17 & -- \\
\hline Spec. Heat, $C_{P}$ & $\mathrm{~J} / \mathrm{kgK}$ & 210 & 353 & 800 \\
\hline Exp. Coef., $\kappa$ & $10^{-6} / \mathrm{K}$ & 5.9 & 4 & 8.6 \\
\hline Modulus, $E$ & $\mathrm{GPa}$ & 52 & 401 & 72 \\
\hline Pois & & 0.41 & 0.291 & 0.22 \\
\hline $\begin{array}{l}\text { Refractive index } \\
\text { @1064nm }\end{array}$ & & 㳊 & $\begin{array}{r}1.6+ \\
\text { i0.05 }\end{array}$ & 1.518 \\
\hline $\begin{array}{l}\text { Refractive index } \\
\text { (a)532nm }\end{array}$ & & $\begin{array}{r}2.72+ \\
\mathrm{i} 0.286 \\
\end{array}$ & $\begin{array}{r}1.98+ \\
\mathrm{i} 0.01 \\
\end{array}$ & 1.518 \\
\hline Melt. Temp., $T_{m}$ & $\mathrm{~K}$ & 1370 & 1903 & 1873 \\
\hline Vap. T & $\mathrm{K}$ & 1403 & 2123 & 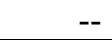 \\
\hline Impedance, $Z$ & $10^{7} \mathrm{~kg} / \mathrm{m}^{2} \mathrm{~s}$ & 1.8 & -- & 1.21 \\
\hline References & & [17-19] & {$[5,18]$} & $\begin{array}{r}{[5]} \\
{[18-19]}\end{array}$ \\
\hline
\end{tabular}




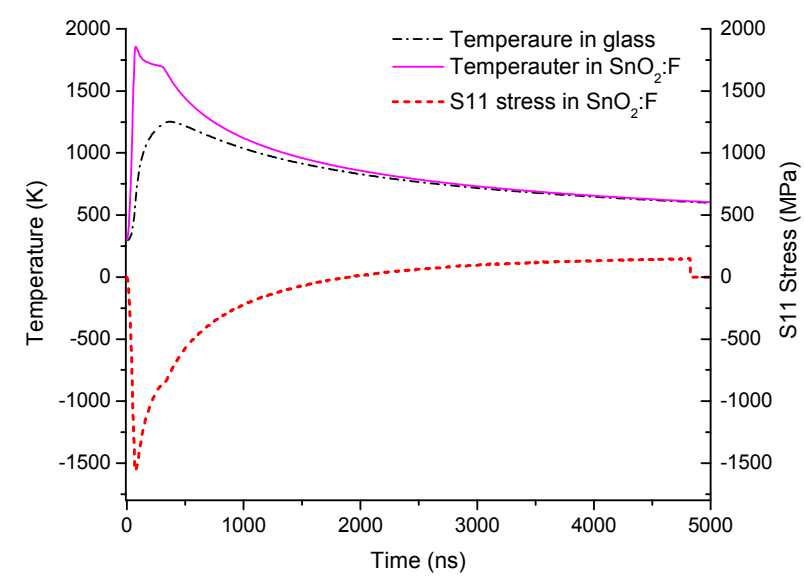

Figure 3. Temperature history of elements in the center part of the $\mathrm{SnO}_{2}: \mathrm{F}$ and glass substrate, and $\mathrm{S}_{11}$ stress evolution of the corresponding $\mathrm{SnO}_{2}: \mathrm{F}$ element, showing a compressive stress in the film at the laser heating period, and the stress transition to tensile due to the glass expansion while heat transferring to glass during film cooling period.

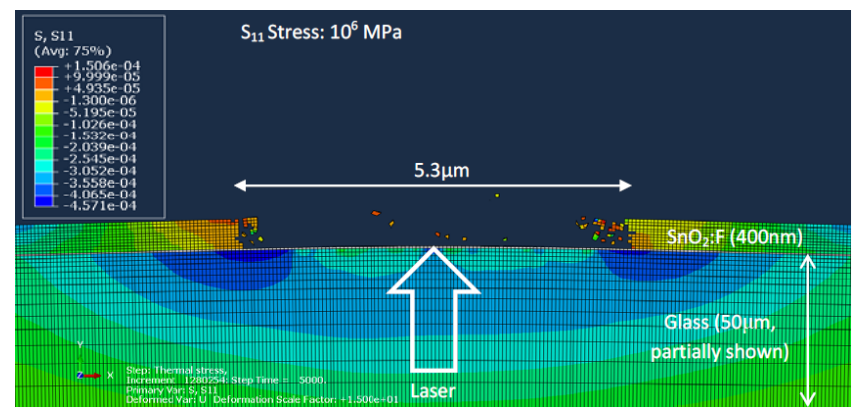

Figure 4. Simulation result of the $\mathrm{SnO}_{2}: \mathrm{F}$ film removal at $5 \mu \mathrm{s}$, showing a removal with a width about $5.3 \mu \mathrm{m}$. Deformation scale is $15 \mathrm{X}$ for viewing clarity.

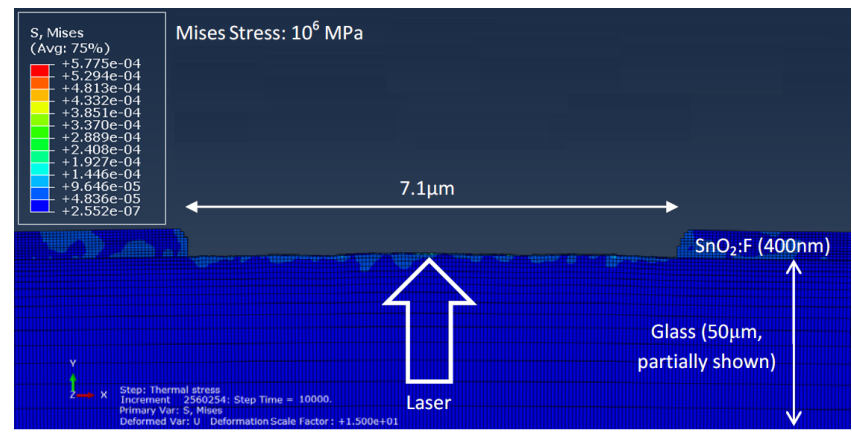

Figure 5. Simulation result of the $\mathrm{SnO}_{2}: \mathrm{F}$ film removal at $10 \mu \mathrm{s}$, showing a removal with a width of $7.1 \mu \mathrm{m}$.

Deformation scale is $15 \mathrm{X}$ for viewing clarity.
In Fig.3, the temperature history output shows that the glass temperature increase has a time delay compared with that of $\mathrm{SnO}_{2}: \mathrm{F}$. This indicates that part of the heat transfers to the glass after the fast laser heating of the film, which leads to the transition from compression to tension in the film. The expansion coefficient of glass is twice of that of $\mathrm{SnO}_{2}: \mathrm{F}$. The temperature change of glass is greater than $\mathrm{SnO}_{2}: \mathrm{F}$ for a unit energy input. Thus, glass expands more than the film while heat is conducted from the film to the substrate. This leads to the decrease of compressive stress, and a transition to tensile stress when the glass expansion exceeds that of the film. Removal of the film at $5 \mu \mathrm{s}$ is depicted in Fig.4, as areas within the film exceed the tensile failure stress. A film removal width of $5.3 \mu \mathrm{m}$ is observed. The film is bent by substrate expansion in the thickness direction and broken by the tensile stress along the $\mathrm{S}_{11}$ direction. The removal process reaches equilibrium and film removal ceases after $10 \mu \mathrm{s}$. As shown in Fig. 5, film removal is clean with a width of $7.1 \mu \mathrm{m}$. As discussed above, the numerical model shows that $\mathrm{SnO}_{2}: \mathrm{F}$ can be removed by laser induced thermal stresses at a lower fluence than the melting threshold.

\section{Experiments on laser scribing of $\mathrm{SnO2:F}$ thin films}

\section{Comparison of scribing from both glass and film sides}

In contrast to the scenario taken by the simulation, industry always makes TCO scribing via laser ablation. Glass side laser scribing results via ablation scenario are shown in Fig. 6 for a film processed at $127 \mathrm{~J} / \mathrm{cm}^{2}$. Optical measurements show that the sidewall is steep, $35 \mu \mathrm{m}$ in width, no positive ridges, and slight substrate damage since the depth of scribe from the top surface is greater than the film thickness (Fig. 6(b)). The sidewall in the SEM crosssection (Fig. 6(c)) suggests that the entire boundary along the scribe line is removed mechanically, not caused by thermal ablation. Plasma removal and brittle crack propagation in the transverse direction resulted in a scribe diameter of $35 \mu \mathrm{m}$. The scribe width is much larger than the spot size and a steep sidewall is formed by a mechanical dominant removal. Film removal quality is estimated by atomic density measurement at the removal area via EDX shown in Fig. 6 (d). Line scanning EDX shows that there is a little residual $\mathrm{Sn}$ after one laser pulse, which may be removed during laser line scanning with a certain pulse overlap. $\mathrm{Si}$ is detected at the undamaged surface because the electron penetration depth of $\mathrm{SnO}_{2}: \mathrm{F}$ is $\sim 1.3 \mu$ which is estimated by [20]

$$
X(\mu \mathrm{m})=0.1 E^{1.5} / \rho
$$

where $\mathrm{E}$ is accelerating voltage $(\mathrm{keV})$ and $\rho$ is density $\left(\mathrm{g} / \mathrm{cm}^{3}\right)$. This observation shows a promising manufacturing process - mechanical dominant removal at the boundary, clean scribe with steep sidewalls. Thus, further simulation work is suggested by considering the phase change with high laser fluences. 


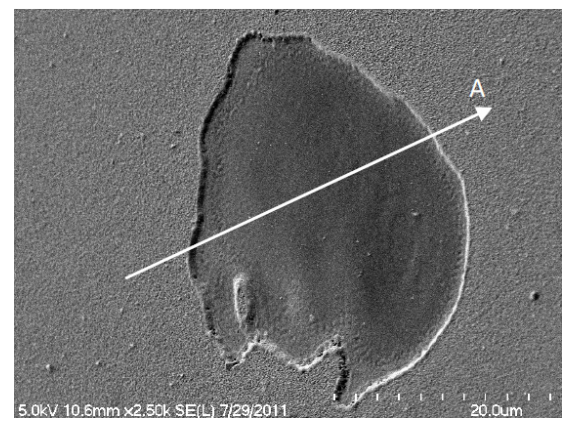

(a) Overview of film removal

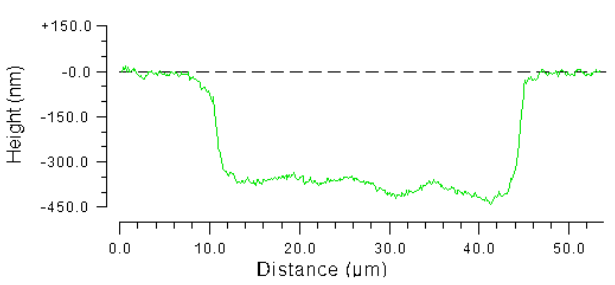

(b) Optical profilometry measurement

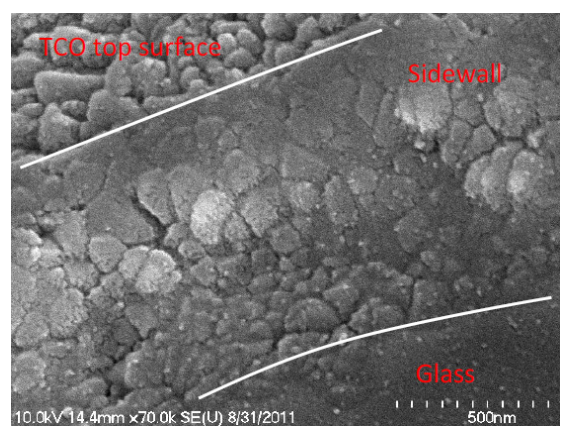

(c) Sidewall of the film removal

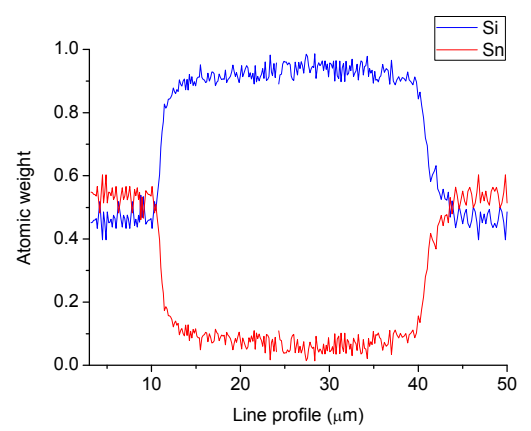

(d) EDX line scan profile

Figure 6. (a) SEM image of the film removal by single pulse processed $\mathrm{SnO}_{2}: \mathrm{F}$ samples from glass side at a fluence of $127 \mathrm{~J} / \mathrm{cm}^{2}$; (b) Removal line profile along A measured by optical profilometry; (c) SEM image of scribe sidewall; (d) EDX line profile scanning along A.
For film-side laser processing, a fluence of $127 \mathrm{~J} / \mathrm{cm}^{2}$ is required to remove the entire film. A 3D scribe profile is taken by optical profilometry shown in Fig. 7 (a). The film is completely removed $(\sim 400 \mathrm{~nm})$ at a width of $50 \mu \mathrm{m}$. It is observed that a positive ridge exists along the scribe line caused by the $\mathrm{SnO}_{2}: \mathrm{F}$ vapor redeposition. This thermal ablation based film removal process is driven by the thermodynamical phase transition of the film material. During thermal ablation, the material is vaporized and ionized, and the plasma is formed. The high pressure caused by the plasma expansion removes the surrounding materials due to brittle cracking; therefore, the scribe width is much larger than the spot size. Some vaporized material redeposit on the high-temperature areas, specifically the melted material at the scribe boundary, via the vapor-liquidsolid (VLS) mechanism [21]. This vapor redeposit is characterized by protruding material around the boundary of the scribe referred to as protruded ridges. The sidewall of a scribed processed from the film side is captured in Fig. 7 (b). It can be seen that the entire sidewall is covered by resolidified material, characterized by the disappearance of the initial granular structure in the side wall. The combined effects of the protruded ridge and melting at the sidewalls indicate film-side laser scribing may lead to undesired electrical properties.

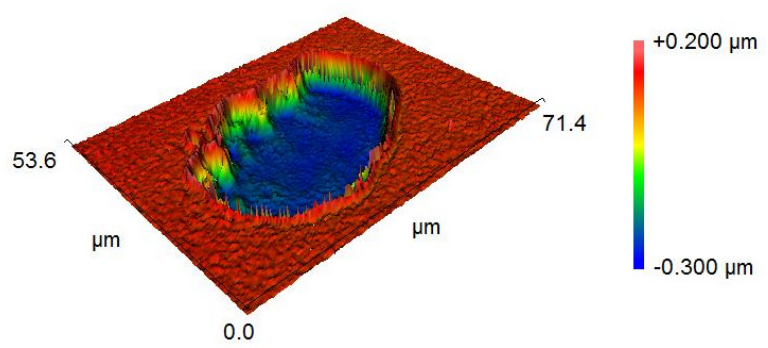

(a) 3D scan profile by optical profilometry

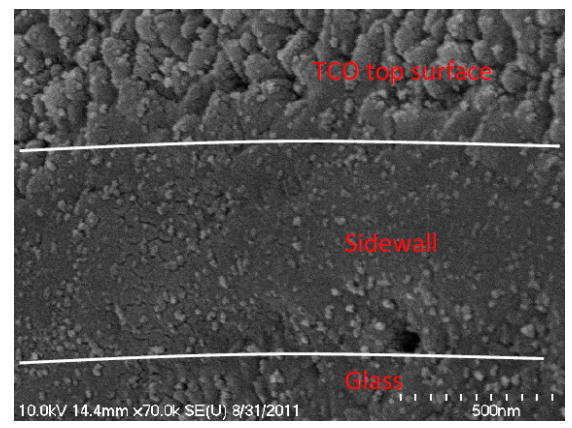

(b) Sidewall of the film removal

Figure 7. (a) 3D scanning of the removal film profile by optical profilometry and (b) SEM image of the sidewall of film removal by single pulse processed $\mathrm{SnO}_{2}: \mathrm{F}$ samples from film side at a fluence of $127 \mathrm{~J} / \mathrm{cm}^{2}$. 


\section{Parametric study on glass-side laser scribing of $\mathrm{SnO}_{2}: \mathrm{F} \mathrm{films}$}

A parametric study on glass-side laser scribing is taken in order to fully understand the mechanisms under different conditions. The relationship between scribe width and depth is shown in Fig. 8 as a function of laser fluence. It is observed that the scribe depth exhibits a linear relationship with increasing fluences until the film is completely removed. The relation between scribe width and fluence is nonlinear, quickly increasing at low fluence up to $20 \mathrm{~J} / \mathrm{cm}^{2}$, constant between $20 \mathrm{~J} / \mathrm{cm}^{2}$ and $60 \mathrm{~J} / \mathrm{cm}^{2}$, and then increases with greater fluences. This transition is indicative of the mechanism transition between film removal processes. At low-fluences (up to $20 \mathrm{~J} / \mathrm{cm}^{2}$ ), the removal mechanism is mechanically dominant. The depth and width of the scribe increase quickly with increased fluence. At mid-fluences $\left(20 \mathrm{~J} / \mathrm{cm}^{2}\right.$ to $\left.60 \mathrm{~J} / \mathrm{cm}^{2}\right)$, thermal ablation removal becomes dominant. An area close to spot size is thermally removed and part of the film is mechanically removed due to thermal stress. At high-fluence range (more than $60 \mathrm{~J} / \mathrm{cm}^{2}$ ), film surrounding the high-pressure vapor is removed by crack propagation, and the sidewalls are formed mainly by mechanical removal.

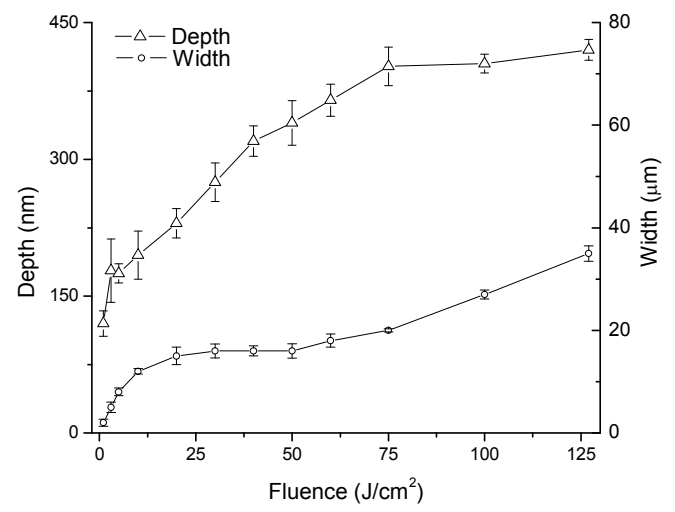

Figure 8. Dependence of removal depth and width on fluence of pulses, error bars indicate standard deviation.

The experimental result of glass-side laser scribing on $\mathrm{SnO}_{2}: \mathrm{F}$ film at $1 \mathrm{~J} / \mathrm{cm}^{2}$ shows that around $140 \mathrm{~nm}$ of the film has been removed with a width of $\sim 2 \mu \mathrm{m}$, which is at the same order of magnitude as the simulation results $(\sim 7 \mu \mathrm{m})$, as shown in Fig. 8. The numerical model is capable of capturing thermal stress induced film removal when the irradiated fluence is less than the damage threshold. Film removal depth and width discrepancies between simulation and experiment may be caused by the assumptions made using numerical coupling, material, and damage parameters in the numerical model. The sequentially thermal mechanical coupling implemented in this work assumes no loss of thermal absorption and transfer during the scribing process. Material removal only occurs in the mechanical model such that heat transfer from non-existent material remains throughout the process. Material properties, such as thermal capacity, conductivity and absorption coefficient, are assumed constant, non-temperature dependent and homogeneous. Brittle cracking is estimated by the tensile thermal stress. The effect on doping of fluorine and other impurities are not considered in the model. The model is likely overestimating the diameter and depth of the scribe due to sequential coupling of thermal and mechanical solutions. A fully coupled scheme is proposed in the future.

The current model is capable of capturing the film removal process. The model shows that the film expands more at the top surface and larger stress is induced due to the different thermal expansion, so that the film starts breaking from top to the bottom, and under a certain condition, partial removal occurs. Moreover, the width of the film removal predicted by the model is the same order of magnitude as the experimental result. Both show the trend of decreasing width with decreasing fluence.

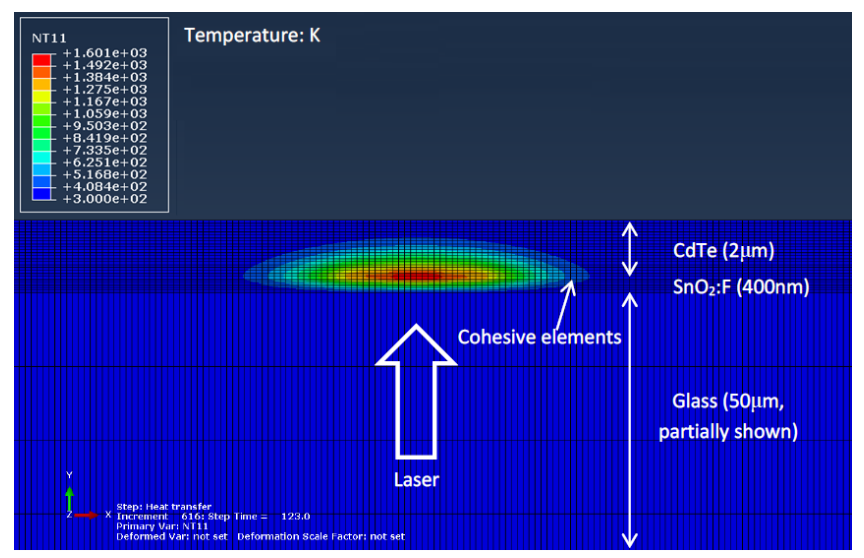

Figure 9. Simulation result of temperature distribution of $\mathrm{CdTe} / \mathrm{SnO}_{2}: \mathrm{F} /$ glass multilayer thermal model at a fluence of $0.2 \mathrm{~J} / \mathrm{cm}^{2}$.

\section{Simulation on CdTe film removal by micro-explosion}

Selective scribing of CdTe film with a thickness of $2 \mu \mathrm{m}$ is performed with a green laser $(532 \mathrm{~nm})$ because it is highly transmitted though $\mathrm{SnO}_{2}: \mathrm{F}$. Laser energy is absorbed within a very thin layer of CdTe due to its small penetration depth $(\sim 167 \mathrm{~nm}$ at the wavelength of $532 \mathrm{~nm})$. CdTe is ionized at the laser focus generating plasma which induces a high pressure at the interface. This high pressure expels and removes the CdTe film from the substrate, and mechanism is known as the micro-explosion induced film removal process.

In this simulation, a 2D model is implemented as shown in Fig. 9, with a $2 \mu \mathrm{m}$ thick CdTe layer on top of $\mathrm{SnO}_{2}: \mathrm{F}$ and glass substrate and a cohesive layer at the $\mathrm{CdTe} / \mathrm{SnO}_{2}: \mathrm{F}$ interface. Material properties are shown in Table 1. The Laser pulse duration is $50 \mathrm{~ns}$ and wavelength is $532 \mathrm{~nm}$. Laser energy estimated by [5] 


$$
E(r, z, t)=\left(1-R_{g}\right)\left(1-R_{t}\right)\left(1-R_{c}\right) \alpha_{c} I(r, z, t) e^{-\alpha_{t} T_{t}} e^{-\alpha_{c}\left(z-T_{t}-T_{g}\right)}
$$

where $R_{c}$ and $\alpha_{c}$ are the reflectivity and absorption coefficient of CdTe, and $T_{t}$ is the thickness of $\mathrm{SnO}_{2}: \mathrm{F}$. Fig. 9 also shows the temperature distribution of laser irradiated from glass side at a fluence of $0.2 \mathrm{~J} / \mathrm{cm}^{2}$. The absorbing volume is located at the interface and a small temperature contour zone in red achieves vaporization temperature of CdTe (1400K). Since glass acts as a confining medium, laser-induced high-pressure plasma is generated at the interface and the corresponding pressure is estimated in Eqs. (8) to (10). The resulting pressure profile, as given in Fig. 10, achieves several hundred MPa at energy levels from $0.2 \mathrm{~J} / \mathrm{cm}^{2}$ to $0.8 \mathrm{~J} / \mathrm{cm}^{2}$ generally used in experiments. This pressure is much larger than the CdTe failure strength.

The temporal and spatial profiles of the plasmagenerated pressure predicted in Fig. 10 and eq. (11) is used in the spatial pressure distribution in the simulation. This pressure is exerted on both $\mathrm{CdTe}$ and $\mathrm{SnO}_{2}: \mathrm{F}$ films at the interface. To consider film peeling, the rest of the interface is simulated with cohesive elements with a thickness of $10 \mathrm{~nm}$. A snapshot of the film and substrate stress state at 21.40ns after the onset of laser pulse is given in Fig. 11. The film is pushed upward due to the plasma pressure, generating $\mathrm{S}_{11}$ tensile stress in the upper region around the film center and the lower part at the edge of the film due to the film deformation. This deformation, at the same time, peels the CdTe film from the $\mathrm{SnO}_{2}: \mathrm{F}$ film underneath, as circled in region A in Fig. 11. Region A is enlarged in Fig. 12 , which shows large $S_{22}$ stress at the interface between the film and substrate. The cohesive elements deform as the film pulled upward. The deformed cohesive elements carry a tensile stress, binding the $\mathrm{CdTe}$ film to the $\mathrm{SnO}_{2}: \mathrm{F}$ substrate, and the surrounding $\mathrm{CdTe}$ and $\mathrm{SnO}_{2}: \mathrm{F}$ elements also experience a tensile $\mathrm{S}_{22}$ stress. It is also observed that $\mathrm{S}_{22}$ tensile stress in the film is smaller than $\mathrm{S}_{11}$ tensile stress; therefore, $S_{11}$ tensile stress is dominant for the CdTe material removal. As the film keeps deforming, the $S_{11}$ tensile stresses at the top center and focal volume boundaries in the film increases, and the film starts breaking at those locations when the tensile stress and total strain reach the $\mathrm{CdTe}$ material removal criteria.

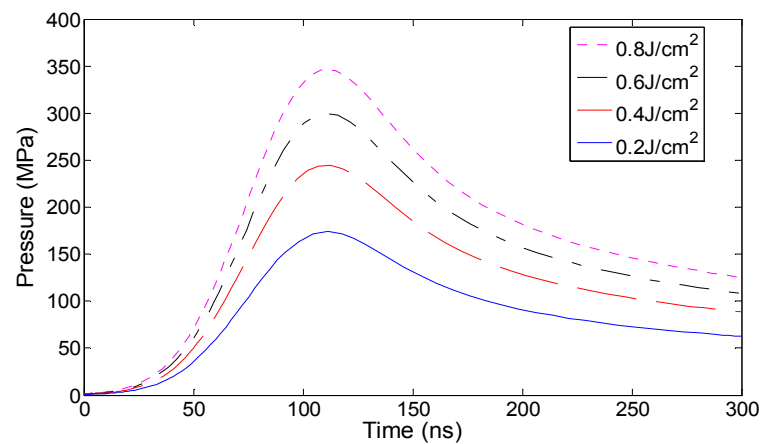

Figure 10. Pressure calculation result at different fluences from $0.2 \mathrm{~J} / \mathrm{cm}^{2}$ to $0.8 \mathrm{~J} / \mathrm{cm}^{2}$.

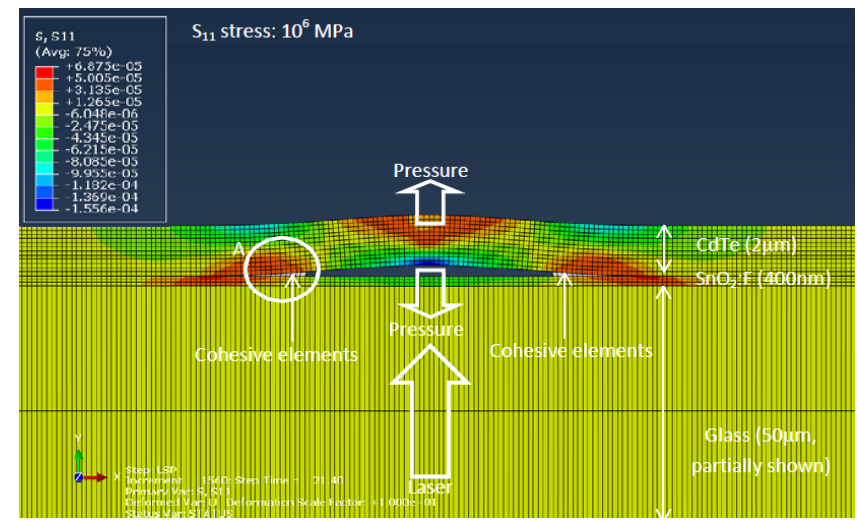

Figure 11. Micro-explosion model with a pressure input at the $\mathrm{CdTe} / \mathrm{SnO} 2: \mathrm{F}$ interface and the plasma dimension is $10 \mu \mathrm{m}$ in width. The CdTe film deforms due to the plasma generated pressure. The snapshot is taken at $21.40 \mathrm{~ns}$. Deformation scale is $10 \mathrm{X}$ for viewing clarity.

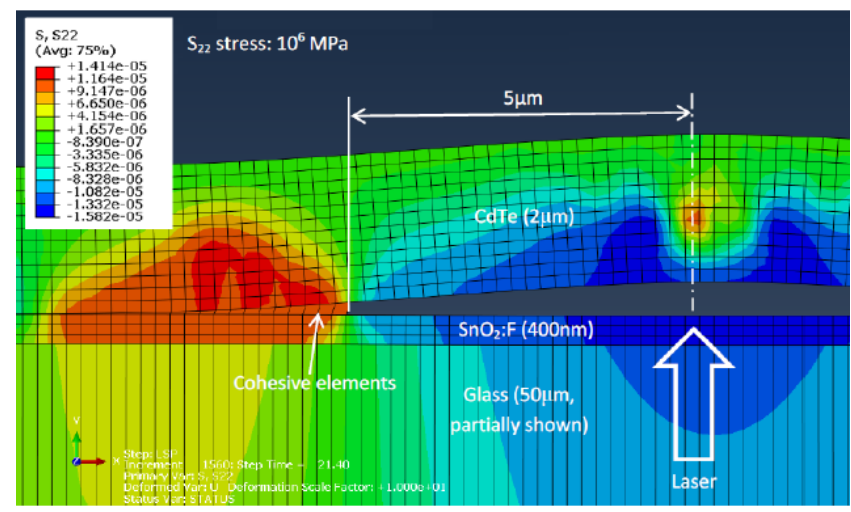

Figure 12. $S_{22}$ stress distribution of the magnified area $A$ in Fig. 11 at the same moment, showing the cohesive elements have been deformed due to $S_{22}$ stress. Deformation scale is $10 \mathrm{X}$ for viewing clarity.

A snapshot at the early stage of the cracking and peeling propagation is taken at $51.51 \mathrm{~ns}$, after the onset of laser pulse, as given in Fig. 13. It is observed that the removal of CdTe material initiates at the top center and the edge of the focal volume with the largest deformation that exceeds the failure strain. Some cohesive elements experiencing large displacement also failed and are removed at the edge of the focal volume, which initiates the delamination process. The stress and strain evolution of a failed CdTe element at the upper part of the film center is given in Fig. 14. It is observed that before the maximum principle stress reaches the failure strength of CdTe, the material undergoes an elastic deformation. After that, the brittle material softening occurs because of micro cracking. The increase of the total strain and decrease of the carried stress become more and more quickly due to the cracking propagation. Once the total strain reaches the designed failure strain, the element is assumed to be fully damaged 


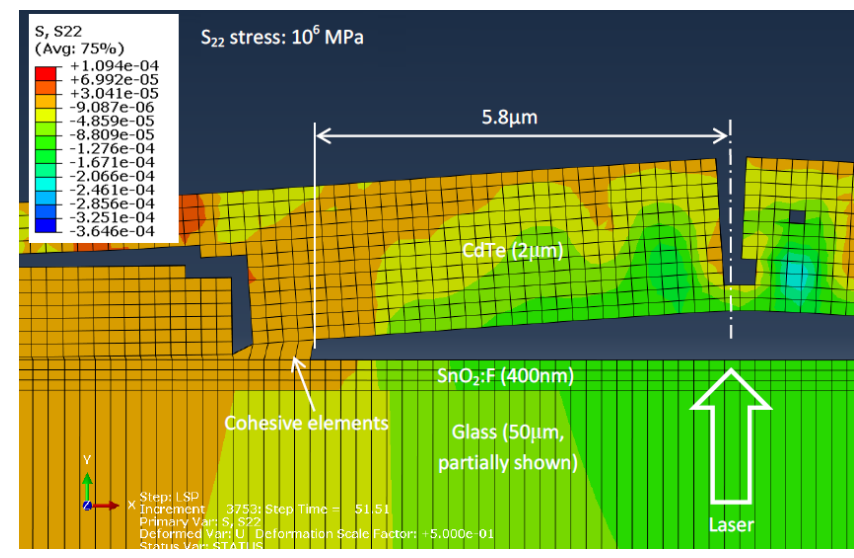

Figure 13. $\mathrm{S}_{22}$ stress distribution of the region shown in Fig. 12 at the later stage $(51.51 \mathrm{~ns})$, showing some cohesive elements have been deleted, enlarging film removal area. Deformation scale is $0.5 \mathrm{X}$ for viewing clarity.

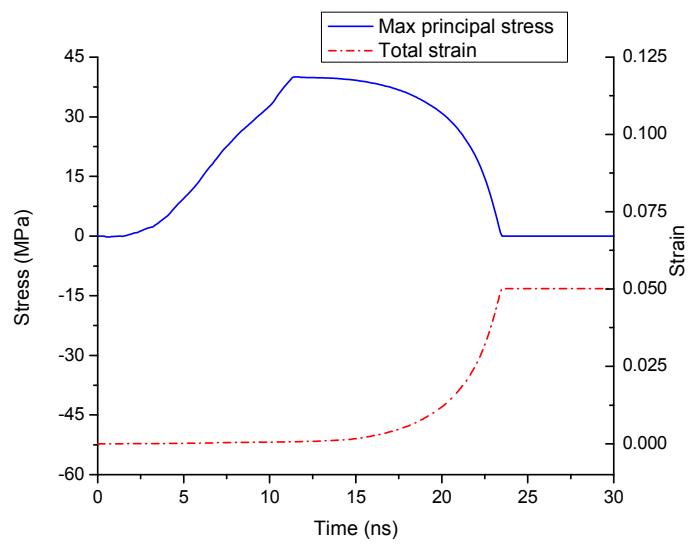

Figure 14. Stress and strain evolution of the failed elements in the upper center part of the CdTe film. The total strain is composed of elastic strain and cracking strain.

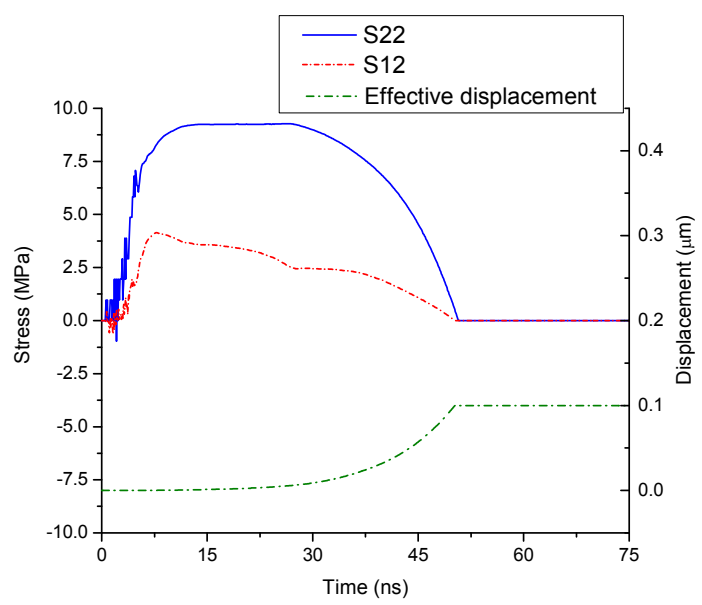

Figure 15. Stress and displacement evolution of the failed cohesive elements. The effective displacement, defined in eq. (7), accounts for the displacement in both normal to the interface and along the shear direction. and is removed from the solution. The shear stress $\mathrm{S}_{12}$ calculated in the simulation is found to be two orders of magnitude smaller than the maximum principal stress; therefore, the material cannot be failed due to the shear behavior. A similar response is assigned to cohesive elements in both extension and shear. The damage initiation of a cohesive element occurs when the stress components satisfy the condition given in eq. (4). However, the stress components do not decrease immediately due to the confinement of both $\mathrm{SnO}_{2}: \mathrm{F}$ and CdTe materials. Once the connected CdTe film undergoes a deformation that is large enough to initiate the stiffness degradation of the cohesive element, the displacement of the cohesive elements increase dramatically. The cohesive element is then removed when this effective displacement, dependent on normal and shear strains, reaches a critical value, as shown in Fig.15. Microexplosion process starts removing the material within an extremely short time $(<25 \mathrm{~ns})$ compared to that of thermal stress dominant film removal $(\sim 5 \mu \mathrm{s})$, because microexplosion occurs during the laser heating period and thermal stress induced removal cannot happen until a limited value of the tensile stress is achieved when the glass expands more than that of the film.

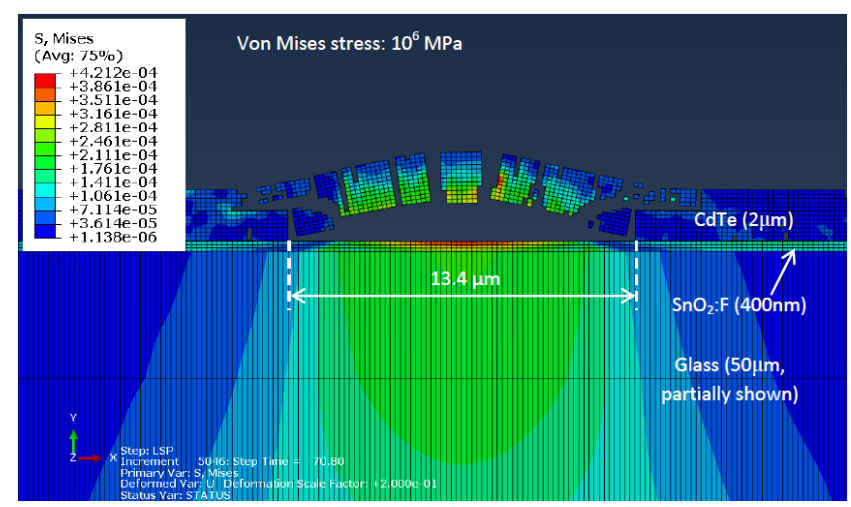

Figure 16. Von Mises stress distribution at 70.80ns, showing the film has been completely removed and the opening width becomes $13.4 \mu \mathrm{m}$ due to the delamination at the cohesive elements. Deformation scale is $0.2 \mathrm{X}$ for viewing clarity.

The late stage of the micro-explosion process is shown in Fig. 16. As film deformation increases, the film breaks into multiple segments, which are expelled by the plasmainduced pressure. Complete material removal is achieved from plasma propagation. The size of the removed film is $13.4 \mu \mathrm{m}$ in width, as shown in Fig. 16. The enlarged opening shows that $3.4 \mu \mathrm{m}$-wide film at the boundaries has been removed due to delamination. The clean removal via simulation investigations indicates that the CdTe film is removed via brittle cracking and delamination processes with non-thermal effects. A similar observation of laser scribing of $\mathrm{ZnO}$ film on glass substrate is presented by Matylitsky, et al. [10]. The micro-explosion model is 
capable of predicting the film removal quality of lowpenetration-depth materials (compared to the film thickness).

\section{CONCLUSION}

Predictive numerical finite element models are demonstrated for glass-side laser scribing of $\mathrm{SnO}_{2}: \mathrm{F}$ and CdTe films. Sequentially-coupled thermal-mechanical model shows that $\mathrm{SnO}_{2}: \mathrm{F}$ film can be removed when the laser fluence is smaller than the damage threshold due to thermal expansion induced stresses. Both experimental and simulation results show that material removal is smaller than the laser spot size and the film starts being removed from the top surface rather than the bottom. Experimental studies show the formation of side walls with limited thermal effect and the elimination of ridges resulting from glass-side laser irradiation. Such properties have been shown to be desirable scribe qualities. A mechanical stress model is developed for glass-side laser scribing of CdTe films, and the stress loading is estimated by the laserinduced shock pressure. A non-thermal material removal process dominated by brittle cracking and delamination of $\mathrm{CdTe}$, as captured by the numerical model, is desired for reducing scribing dead zones and interlaminar shorts. Such a process is highly desired for its improved scribe quality and greater process efficiency. Numerical models investigated in this work are capable of predicting the material removal dynamics and fracture behavior of $\mathrm{SnO}_{2}: \mathrm{F}$ and CdTe. Further numerical developments are aimed at predictively modeling the scribing line profile by taking account of the laser pulse overlapping.

\section{ACKNOWLEDGMENTS}

The use of material characterization equipment at Material Research Science and Engineering Center, Columbia University is gratefully acknowledged. The authors also would like to thank Pilkington North America Inc. for providing $\mathrm{SnO}_{2}: \mathrm{F}$ coated samples.

\section{REFERENCES}

[1] Dhere, R.G., et al., 2011, CdTe solar cell with industrial Al:ZnO on soda-lime glass, Thin Solid Films, 519/21: $7142-7145$.

[2] Luque, A., Hegedus, S., 2003, Handbook of Photovoltaic Science and Engineering, Wiley, UK.

[3] Compaan, A.D., Matulionis, S.N., 2000, laser scribing of polycrystalline thin films, Optics and Lasers in Engineering, 34: 15-45.

[4] Murison, R., et al., 2010, CIGS P1, P2 and P3 laser scribing with an innovative fiber laser, $35^{\text {th }}$ IEEE Photovoltaic Specialists Conference, 179-184.

[5] Bovatsek, J., Tamhankar, A., Patel, R.S., Bulgakova, N.M., Bonse, J., 2010, Thin film removal mechanisms in ns-laser processing of photovoltaic materials, Thin Solid Films, 518/10: 2897-2904.

[6] Gecys, P., Raciukaitis, G., 2010, Scribing of a-Si thin film solar cells with picoseconds laser, Eur. Phys. J. Appl. Phys., 51: 33209.

[7] Wang, W., Wang, K.D., Jiang, G.D., Mei, X.S., Yang, C.J., 2010, Comparison of femtosecond laser-induced front- and rear-side ablation of films, Proceedings of the Institution of Mechanical Engineers, Part B: Journal of Engineering Manufacture, 225/4: 520-527.

[8] Beyer, S., Tonrnari, V., Gornicki, D., 2003, Comparison of laser induced front- and rear side ablation, Proceedings of SPIE, 5063: 202-207.

[9] Sano, T., Yamada, H., Nakayama, T., Miyamoto, I., 2002, Laser induced rear ablation of metal thin films, Proceedings of SPIE, 4426: 70-73.

[10] Matylitsky, V.V., Huber, H., Kopf, D., 2011, Selective removal of transparent conductive oxide layers with ultrashort laser pulses: front- vs. back-side ablation, International Congress on Applications of Lasers \& Electro-Optics, M903: 1022-1027.

[11] Rankine, W.J.M., 1858, A Manual of Applied Mechanics, Richard Griffin and Company, London, UK.

[12] Abaqus Theory Manual, version 6.11, 2011, Providence, RI, Dassault Systemes Simulia Corp.

[13] Carlomagno, G.M., Brebbia, C.A., 2011, Computational Methods and Experimental Measurements XV, WIT Press, Southampton.

[14] Camanho, P.P., Dávila, C.G., 2002, Mixed-mode decohesion finite elements for the simulation of delamination in composite materials, NASA Langley Research Center, TM-2002-211737: 1-37.

[15] Zhang, W., Yao, Y. L., 2002, Micro-scale laser shock processing of metallic components, ASME Trans. J. of Manufacturing Science and Engineering, 124/2: 369378.

[16] Fabbro, R., Fournier, J., Ballard, P., Devaux, D., Virmont, J., 1990, Physical study of laser-produced plasma in confined geometry," J. Appl. Phys., 68/2: 775-784.

[17] Peter, C., 1994, Properties of Narrow Gap CadmiumBased Compounds, the Institution of Electrical Engineers, UK.

[18] Luque, A., Hegedus, S., 2011, Handbook of Photovoltaic Science and Engineering, $2^{\text {nd }}$ Edition, John Wiley \& Sons, Ltd. UK.

[19] Assay, J.R., Shahipoor, M., 1992, High-Pressure Shock Compression of Solids, New York, SpringerVerlag.

[20] Potts, P.J., 1987, A Handbook of Silicate Rock Analysis, Chapman and Hall, London, UK.

[21] Lowndes. D.H., Fowlkes, J.D., Pedraza, A.J., 2000, Early stage of pulsed-laser growth of silicon microcolumns and microcones in air and SF6, Applied Surface Science, 154-155: 647-658. 